\title{
A Comparative Genre-Based Analysis of Move-Step Structure of RAIs in Two Different Publication Contexts
}

\author{
Sultan H. Alharbi ${ }^{1}$ \\ ${ }^{1}$ Department of English Language \& Translation, College of Languages \& Translation, King Saud University, \\ Riyadh, Saudi Arabia \\ Correspondence: Sultan H. Alharbi, Department of English Language \& Translation, College of Languages \& \\ Translation, King Saud University, Riyadh, Saudi Arabia.
}

Received: January 10, 2021

Accepted: February 4, 2021

Online Published: February 8, 2021

doi: $10.5539 /$ elt.v14n3p12

URL: https://doi.org/10.5539/elt.v14n3p12

\begin{abstract}
This genre-based study investigates the move-step structure of two sets of English-medium research article introductions (RAIs) in the field of applied linguistics using Swales' $(1990,2004)$ Create a Research Space (CARS) model of move/step analysis. A corpus of 30 RAIs from two English-medium research articles (15 International and 15 Local) was selected. The international research articles written for an international readership were selected from the journal English for Specific Purposes, while the local research articles, written for local readers, were selected from Arab World English Journal. The findings indicated that although the three moves suggested by the CARS (Swales, 1990, 2004) model appeared in the two subcorpora, some variation was observed with respect to the range of moves employed in each subcorpus. As expected, Move 2 was not always found in texts in the Local subcorpus. In terms of steps and sub-steps analysis, the findings showed the three steps and sub-steps of Move 1 are conventional in the International and Local applied linguistics RAIs. Further, while M2-S1B is conventional and M2-S1A is optional in the Local subcorpus, these two sub-steps of Move 2 are conventional in the International subcorpus. There were no striking differences between the two subcorpora with regard to the employment of the proposed steps of Move 3. Limitations and the implications of the findings, as well as recommendation of some suggestions for future research are provided.
\end{abstract}

Keywords: RAIs, move-step, applied linguistics, International, local, corpora

\section{Introduction}

A considerable amount of work has been done on introductions compared to the other sections in academic texts (e.g., Bunton, 2002; Kawase, 2018; Loi, 2010; Ono, 2017; Ozturk, 2007; Samraj, 2002, 2008; Sheldon, 2011; Soler-Monreal, 2016; Swales, 1990, 2004). The interest in studying introductions in academic writing may be due to the fact that they play an influential role in displaying the relevance of the research about to be reported in the current work to previous work in the field (Bhatia, 1993). Therefore, unlike the abstract that, for instance, provides the reader with only an account related to the work itself (e.g., methods, findings), the introduction goes a step further and gives the readership more details such as how the current work is relevant to research in the specific field within which it is situated. Furthermore, Swales (1990) also points out that introductions can be troublesome to compose, and writers have duly experienced difficulties when writing their introductions. Thus, Swales $(1990,2004)$ initially proposed a three-move model for analysis of RAIs, which is termed the Create a Research Space (CARS) model. Swales considered that RAIs consist of activities at each stage. The notion of move and step is conceptualised in his model. "A 'move' in genre analysis is a discoursal or rhetorical unit that performs a coherent communicative function in a written or spoken discourse" (Swales, 2004, p. 228). In other words, "[a] move is to be considered as a genre stage which has a particular, minor communicative purpose to fulfil, which in turn serves the major communicative purpose of the genre" (Santos, 1996, p. 485). A "step" is regarded as a sub-move, since it is situated under each move. Individual steps have a particular communicative purpose that is related to the communicative purpose that each move contains (Dudley-Evans \& St John, 1998). The CARS scheme has a hierarchal and interactive structure by combining moves and steps in the introduction effectively and sensibly, as will be discussed in detail in Section (1.1).

Following Swales' $(1990,2004)$ CARS model, a large number of studies have analyzed the structural organization of RAIs in English, using Swales" (1990, 2004) model of "move" and "step" as a framework for 
genre-analytic research. Two types of studies were found in the previous literature that employed the CARS model in analysing the move structure of the RAIs. The first set of studies is CARS studies in English, which were conducted for the purpose of validating the CARS model as an analytic and teaching tool, as well as exploring disciplinary variations (Anthony, 1999; Bunton, 2002; Crookes, 1986; Dudley-Evans, 1986, 1993; Ozturk, 2007; Samraj, 2002, 2004, 2005, 2008; Swales \& Najjar, 1987). The second group of studies is CARS cross-cultural studies, where other languages were studied and compared to English (e.g., Ahmad, 1997; Al-Qahtani, 2006; Árvay \& Tankó, 2004; Duszak, 1994; Fakhri, 2004; Hirano, 2009; Jogthong, 2001; Lee, 2000; Loi, 2010; Najjar, 1990; Sheldon, 2011; Soler-Monreal et al., 2011; Taylor \& Tingguang, 1991). Overall, Swalesian move analysis of RAIs has found that each of the moves often occurs in RAIs regardless of the discipline and the language, but preferred steps for the realisation of each move and the degree of emphasis on each move vary among disciplines and languages used.

However, to the best of the researcher's knowledge and as evidenced by the relevant literature reviewed, few studies have explored the impact of the publication context on writing RAIs. Research has shown that RAIs are influenced, to some extent, by sociocultural variables and the specific features of the socio-pragmatic context in which the texts were produced (i.e., local constraints). For example, there is a tendency to avoid direct confrontation by writers in local English journals in contrast with the more combative stance adopted by writers of some RAIs published in international English-medium journals. Therefore, the current study aims to investigate the move-step structure of RAIs in the field of applied linguistics in English-medium journals in two different discourse communities (International vs. Local), drawing on Swales' $(1990,2004)$ move-step model for RAIs, and seeking to answer the following research questions:

1) Are there any differences between International and Local applied linguistics RAIs in terms of the employment of the three moves proposed in Swales' $(1990,2004)$ move-step model?

2) Are there any differences between International and Local applied linguistics RAIs in terms of the employment of the steps and sub-steps proposed in Swales' (1990, 2004) move-step model?

\subsection{Swales' (1990, 2004) CARS Model for RAIs}

Move-step analysis in this study was conducted following the model proposed by Swales (1990), i.e., Create a Research Space (CARS) model for RAIs. In this model, there are three obligatory moves which, in turn, are realised by a number of obligatory and optional steps. These rhetorical moves are: [Move 1] establishing a territory, [Move 2] establishing a niche, [Move 3] presenting the present work. According to this model, RAIs often begin with a move that establishes the general topic being discussed. In this move, the centrality of the topic within the field may be presented. Writers then create a niche for themselves within this territory in several ways, e.g., pointing out a gap in previous research, which then gives a justification for the research about to be stated; in such, counterclaiming, question-raising or continuing a tradition could alternatively be employed by writers to create a research space. In the final move, writers indicate how their contribution will fill in the space, i.e., niche. Also, they can outline their research purposes, announce the present research or the principal findings, or can indicate RA structures (Swales, 1990, p. 141).

Acknowledging the findings and the observations of some studies (Anthony, 1999; Kanoksilapatham, 2003; Samraj, 2002) that employed the model, Swales (2004) has made still further modifications to his (1990) CARS model in order to make it suitable to describe RAIs of various disciplines. Figure 1 shows Swales' (2004) modified CARS model for RAIs. Overall, Swalesian move analysis of RAIs has found that each of the moves often occurs in RAIs regardless of the discipline and the language, but preferred steps for the realization of each move and the degree of emphasis on each move vary among disciplines and languages used. 


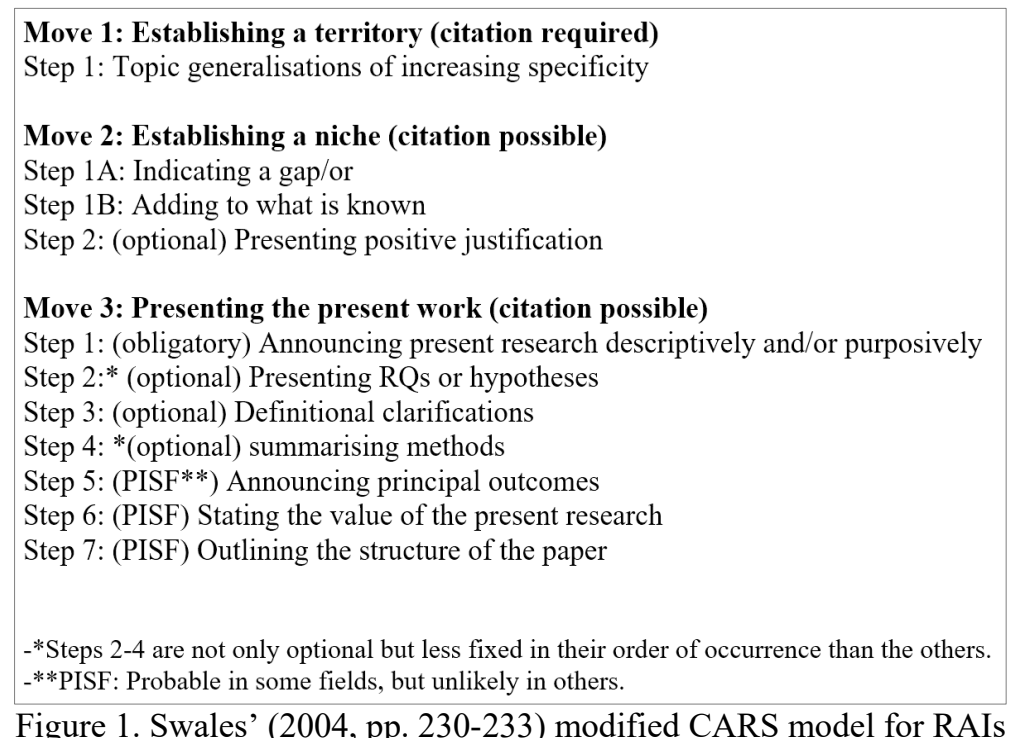

\section{Methods and Procedures}

\subsection{Corpus}

The corpus used in the current study comprised 30 RAIs appearing in two English-medium journals of applied linguistics, namely, English for Specific Purposes (ESPj) and Arab World English Journal (AWEJ). The decision to focus on these two journals is because the current study is interested in applied linguistics in relation to English language teaching, since applied linguistics is a diverse and contested area (Yang \& Allison, 2003). ESPj was chosen as a representative of international journals in the current study because it is one of the established journals in applied linguistics (Yang \& Allison, 2003, p. 266). As for AWEJ, it is a peer-reviewed journal, whose goal is to promote the learning and teaching of English in the Arab World. AWEJ, being selected as a representative of local research outlets, has been recently accepted for indexing in the Emerging Sources Citation Index (ESCI). Journals in ESCI are selected based on several criteria, one of which is journal quality. Despite the similarities that might exist between the RAIs in these two journals and the communicative function they serve, they seem to be different because they are written for different target audiences; while ESPj addresses an international community, the immediate audience is the local community in the Arab world due to the scope of the topics covered by the journal. It should be noted here that the 30 RAs chosen for the current study were written within a time span of three years (2010-2015) because research has shown that the rhetorical structure of RA may change over time (Crookes, 1986). The complete list of International (Intl.) and Local RAs included in the present study can be found in Appendix A.

\subsection{Analytical Procedure}

Identification of the RAIs in the corpus of the present study was relatively straightforward, as it was found that all the introductions were explicitly indicated by the use of the label "Introduction" at the beginning of the research articles. The 30 RAIs were examined for moves, steps, and sub-steps already detected and described in the literature. In particular, at the level of moves, the three recognized moves in Swales' $(1990,2004)$ CARS model were utilized as a starting point for analysis. Earlier studies have demonstrated that the CARS model is a valid and useful tool for analyzing academic text introductions such as RAs (e.g., Ahmad, 1997; Anthony, 1999; Fakhri, 2004; Hirano, 2009; Ozturk, 2007). At the level of steps and sub-steps, all those identified by Swales (2004) and Samraj $(2002,2004,2005)$ were also considered. For instance, Samraj (2002, p. 4) found that centrality claims, which establish the importance of the area of research in Move 1, are made either by "assertions about the importance of the topic being discussed or by assertions concerning active research activity in the area concerned." Also, Samraj found that in Move 1, which establishes the general topic being discussed, writers provide topic generalizations about the field and/or give general and background information with or without reference to previous research. Moreover, Samraj suggested that Move 2 (establishing a niche) could be realized in other ways rather than by means of creating a space/niche for the study in the context of an established body of previous literature of a given field. Samraj found that Move 2 in the texts she analyzed is realized differently in that the research is also justified in terms of real-world matters. 
For consideration of the reliability of analysis in the current study, it was essential to involve a second rater who independently analyzed more than $25 \%$ of the corpus from the two sets of RAIs. The second rater, who was an applied linguistics professor and was familiar with the CARS model, was requested to note problematic cases where the taxonomy failed to work. After the second rater finished coding the sets of RAIs, we agreed to meet to discuss our analyses and debate the disagreements that were found between us. We first used the "simple percentage agreement" to calculate the inter-rater reliability (Mackey \& Gass, 2005). That is, the percentage of agreement was calculated using the formula: Number of agreements/(number of agreements + number of disagreements $) \times 100=$ percentage of agreement. The total percentage of agreements between the second rater and me for all of the RIAs analysed exceeded $92 \%$, which is very good in qualitative research (e.g., Mackey \& Gass, 2005; Miles \& Huberman, 1994). Table 1 presents the final taxonomy of RAIs employed for analysis in the present study.

In order to classify and justify the moves/steps found in the RAIs examined in this study, the present study also follows the frequency of occurrence defined by Kanoksilapatham (2005), who attempted to classify moves into three categories: Obligatory, conventional, and optional moves. According to Kanoksilapatham, a move is obligatory if it appears in $100 \%$ of the corpus, a move is optional if it appears less than $60 \%$ of the corpus, and moves appeared in 60-99\% of the corpus as conventional moves. He also added that, "The high cut-off frequency of $60 \%$ would be beneficial in enhancing the distinction between the two categories of moves" (Kanoksilapatham, 2005, p. 272).

Table 1. Final taxonomy of RAIs used for analysis in the present study

\author{
Move 1 (M1): Establishing a territory \\ Step 1 (M1-S1): Claim centrality \\ Step 1 (M1-S1A): Importance in research \\ Step 1 (M1-S1B): Importance in real world \\ Move 2 (M2): Establishing a niche \\ Step 1 (M2-S1A): Gap/question in research \\ Step 1 (M2-S1B): Problem/need in the real world

\section{Move 3 (M3): Presenting the present work} \\ M3-S1: (outlining purposes, or announcing present research) \\ M3-S2: (announcing principal findings) \\ M3-S3: (indicating RA structure) \\ M3-S4: (presenting RQs or hypotheses) \\ M3-S5: (definitional clarifications) \\ M3-S6: (summarizing methods) \\ M3-S7: (stating the value of the present research)
}

Step 2 (M1-S2): Present topic generalisations and/or background information

\title{
3. Results and Discussion
}

This section presents the findings of the analysis of 30 International and Local applied linguistics RAIs in terms of the moves, steps, and sub-steps utilized to actualize the moves, as well as provides some explanations for the main findings. It should be noted that extracts from the texts analyzed will be included where appropriate.

Before presenting the findings of the analysis of moves, steps, and sub-steps, I provide some descriptive information about the RAIs in both data sets. The findings indicated that there are some differences existing between the two corpora when considering formal aspects. That is, the RAIs present a great deal of variability in their length. The international RAIs were longer and included more sections and sub-sections, ranging from 1 to 6 pages (average 3.5). On the other hand, the local RAIs were shorter, ranging from 1 to 3 pages (average 1.8). The number of words of the individual International and Local RAIs ranged, respectively, from 304 to 2,372 (average 1,234.7), and 220 to 1,550 (average 541.5) words. The variation among the two subcorpora is discussed later in this section. 


\subsection{Move Analysis}

The three moves proposed by the CARS (Swales, 1990, 2004) model were found in both groups of RAIs, as can be seen in Figure 2 below. However, the two sets of texts showed variation with respect to the range of moves employed in each subcorpus. The International RAIs contained 7 to 22 moves and the Local ones contained 4 to 16 moves. This variation among the two sets of RAIs may be attributed partly or wholly due to the length of the RAIs included in the two subcorpora, as evident from the average number of words of RAIs of each group: $(1,234.7)$ for International RAIs and (541.5) for Local RAIs.

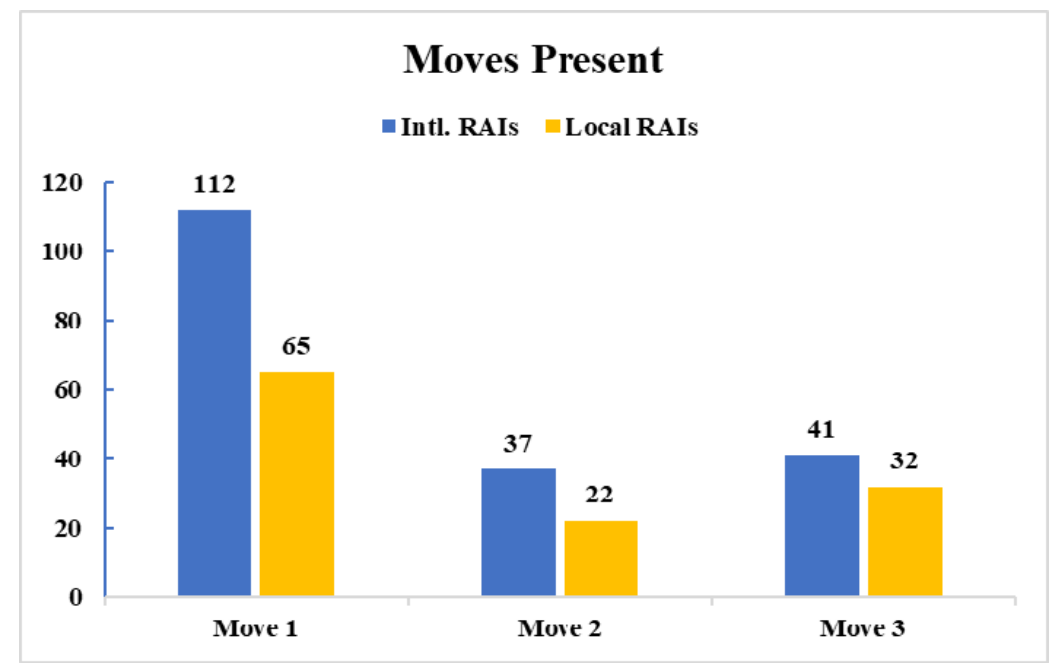

Figure 2. Move present in RAIs

Moreover, as predicted in the CARS (Swales, 1990, 2004) model, except for two RAIs in the International sub-corpus, the rest (i.e., 28 RAIs) started with Move 1 (establishing a research territory) and ended with Move 3 (presenting the present work). This finding is consistent with past studies, which indicated that RAIs tend to start off with Move 1 and close with Move 3 (e.g., Hirano, 2009; Loi, 2010; Ozturk, 2007; Sheldon, 2011). As for the two International texts that did not follow the [Move 1 - Move 2 - Move 3] sequence strictly, Intl.-13 commenced with Move 3 (Ex. 1) and ended with Move 1 (Ex. 2), whereas Intl.-7 closed with Move 1 (Ex. 3 ).

Ex. 1 The present study came about in response to a request by the Department of Accounting to ESP/language specialists in an institution of tertiary education in New Zealand. (Intl.-13)

Ex. 2 Research has begun to focus on the kinds of incidental language-learning opportunities that may be present in subject teaching in higher education (Pecorari, Shaw, Irvine, \& MalmstrTm, 2011). (Intl.-13)

Ex. 3 These are strong indications that also beliefs, conditioned by individual differences such as motivation, personality and learning style, and in turn consequential for learning behavior and strategy preferences, may have some discipline-specific variations. (Intl.-7)

As can be seen in Table 4 and Table 5, though employed in every RAI in the International subcorpus, Move 2 was not always present in every RAI, since four texts in the Local subcorpus (Local-1, Local-9, Local-11, Local-13) lack the move. This finding is not surprising, since previous studies on RAIs revealed that Move 2 did not always appear in every RAI in texts analysed from diverse disciplines (e.g., Ahmad, 1997; Al-Qahtani, 2006; Jogthong, 2001; Najjar, 1990; Taylor \& Tingguang, 1991).

\subsection{Steps and Sub-Steps Analysis}

Some variations were observed when considering the steps (S) that are used to realise the moves in the two subcorpora and the number of RAIs including them. Therefore, this section will discuss the similarities and differences with relation to each of the three moves. While section 3.2.1 focuses on steps (S) in Move 1, Section 3.2.2 and Section 3.2.3 deal with these steps (S) in Move 2 and Move 3, respectively.

\subsubsection{Steps and Sub-Steps in Move 1 (Establishing a Territory)}

As can be seen in Table 2 and Table 3, M1-S1B, which establishes the importance of the topic being discussed in terms of its importance in the real world, appeared in 14 RAIs in the International subcorpus (Ex. 4) and in 12 ones in the Local subcorpus (Ex. 5). On the other hand, M1-S1A, which establishes the importance of the area 
concerned in terms of active research activity, was less used in both sets of texts (Ex. 6 and Ex. 7). M1-S1A was used 19 and 16 times in the International and Local RAIs, respectively, and similarly in 10 RAIs in each group.

Ex. 4 For contemporary scholars, the need to publish scientific papers has become ever more pressing if promotion and professional advancement are to be achieved. In order to get their papers accepted, researchers need to meet the expectations of the members of their particular disciplinary communities, especially those of the editors and reviewers of international English language journals in which the degree of competitiveness continues to grow (Hanauer \& Englander, 2011; Lillis \& Curry, 2010). (Intl.-5)

Ex. 5 With the increasing need and ceaseless interest in learning English as a second language, it is important to study and understand the factors that can affect the learning process. Among some of the most prominent factors are participants ${ }^{e e}$ attitudes and perceptions towards the foreign language. (Local-5)

Ex. 6 In recent decades a considerable amount of research has been dedicated to the non-native English speaker scholar writing for publication in English (Ferguson, 2007; Flowerdew, 2000, 2001; Lillis \& Curry, 2006; Moreno, Rey-Rocha, Burgess, López- Navarro, \& Sachdev, 2012; Pérez-Llantada, Plo, Ferguson, \& Gibson, 2011; Salager-Meyer, 2008; to list just a few). (Intl.-8)

Ex. 7 Second language (L2) vocabulary learning has been frequently researched topic in the last three decades (Alharthi, 2014a; Bogaards \& Laufer, 2004; Coady \& Huckin, 1997; Laufer \& Rozovaski-Roitblat, 2014; Meara, 1980; Milton, 2009; Nation, 1990, 2001; Nation \& Webb, 2011; Peters, 2013; Schmitt, 2008, 2010; Tian \& Macaro, 2012; Webb \& Chang, 2015). (Local-14)

Table 2. Steps and sub-steps in Move 1 (Establishing a territory) in Intl. RAIs

\begin{tabular}{llllllllllllllllll}
\hline Intl. RAs & 1 & 2 & 3 & 4 & 5 & 6 & 7 & 8 & 9 & 10 & 11 & 12 & 13 & 14 & 15 & Total & \# of RAs \\
\hline M1-S1A & & 1 & 1 & 3 & 1 & & 1 & 2 & 2 & & 2 & 4 & 2 & & & 19 & 10 \\
M1-S1B & 1 & 1 & 1 & 2 & 1 & 3 & 3 & & 4 & 3 & 2 & 1 & 4 & 6 & 3 & 35 & 14 \\
M1-S2 & 2 & 2 & 4 & 5 & 3 & 3 & 4 & & 6 & 3 & 2 & 4 & 5 & 8 & 7 & 58 & 14 \\
Total & 3 & 4 & 6 & 10 & 5 & 6 & 8 & 2 & 12 & 6 & 6 & 9 & 11 & 14 & 10 & 112 & \\
\hline
\end{tabular}

Table 3. Steps and sub-steps in Move 1 (Establishing a territory) in Local RAIs

\begin{tabular}{llllllllllllllllll}
\hline Local RAs & 1 & 2 & 3 & 4 & 5 & 6 & 7 & 8 & 9 & 10 & 11 & 12 & 13 & 14 & 15 & Total & \# of RAs \\
\hline M1-S1A & 2 & & 1 & & 2 & & 2 & 2 & 1 & 1 & 1 & 1 & & 3 & & 16 & 10 \\
M1-S1B & & 1 & 2 & 1 & 2 & 1 & 1 & 3 & 1 & 2 & 2 & & & 1 & 3 & 20 & 12 \\
M1-S2 & 2 & 2 & 2 & 1 & 2 & 1 & 3 & 5 & & 4 & & 1 & 1 & 4 & 1 & 29 & 13 \\
Total & 4 & 3 & 5 & 2 & 6 & 2 & 6 & 10 & 2 & 7 & 3 & 2 & 1 & 8 & 4 & 65 & \\
\hline
\end{tabular}

The second step, M1-S2, which provides topic generalizations about the field and/or gives general and background information, was present in 14 and 13 RAIs in the International and Local subcorpora, respectively. The following excerpts (Ex. 8 and Ex. 9) are from the writers' works in both sets of texts. However, there are striking differences between both sets of RAIs in terms of the total number of M1-S2 instances used. That is, as Table 2 and Table 3 show, the frequency of instances of M1-S2 in the International subcorpus is almost double the number of these instances in the Local subcorpus.

Ex. 8 Two specific concerns about the degree to which the group oral can provide opportunities for test takers to demonstrate their abilities to discuss a topic have been raised. The first is that test takers could choose to pay little attention to what others in the group are saying, opting instead to plan what they will say next (He \& Dai, 2006)... (Intl.-6)

Ex. 9 Within these approaches, many researchers stipulate that the entire initial state in the acquisition of a second language is constrained and defined in whole or in part by the learner's L1 grammar (Full Access/Full Transfer Hypothesis) (see e.g., Hawkins \& Chan, 1997; Schachter, 1990). Other researchers have proposed that transfer is mainly restricted to lexical categories (see Vainikka \& Young-Scholten, 1996), while a third group assumes an intermediary position, suggesting that all 
of "L1 grammar is transferred except the value of formal features under functional heads" (Eubank, 1996, cited in Craats, 2002, p. 37). (Local-1)

This finding suggests that the three steps and sub-steps of Move 1 are conventional (Kanoksilapatham, 2005) in applied linguistics RAIs because they occurred in more than $60 \%$ of texts in each subcorpus. It seems that it is a common strategy in order to establish the importance of the topic being studied in the RAIs analysed in terms of both research activity in the area (M1-S1A) and real-world matters (M1-S1B). Further, M1-S2, which makes a topic generalisation and/or gives background information, can be regarded as crucial in the realisation of Move 1 in the two subcorpora. M1-S2 is the most frequently used step of Move 1 in the two groups of texts, both in terms of the RAIs including them and its number of occurrences (Table 2 and Table 3). This finding is consistent with those of other studies conducted on RAIs (e.g., Ozturk, 2007; Samraj, 2002), which reported no or little variation between disciplines and languages in the employment of M1-S2. Also, the presence of more instances of M1-S2 may also explain the difference in the length of the RAIs included in the two subcorpora. This means that writers of the International RAIs, unlike those of Local RAIs, are more interested in providing their wider international readership, who may not possess the same background knowledge of the topic being researched, with this needed information.

\subsubsection{Steps and Sub-Steps in Move 2 (Establishing a Niche)}

As can be seen in Table 4 and Table 5, M2-S1A (Ex. 10 and Ex. 11) and M2-S1B (Ex. 12 and Ex. 13), which are used to actualize Move 2, appeared in the two sets of applied linguistics RAIs, although more occurrences of these sub-steps are found in the International RAIs.

Ex. 10 However, many of these studies focus on traditional written texts (e.g., Grabe \& Kaplan, 1996; Hoey, 2001; McLoughlin, 2000; Reah, 1998), and there is still relatively little on the newer channels of communication, such as e-mail, text-messaging, voice-mail and mobile phones (e.g., Gimenez, 2000, 2006; Jensen, 2009; Shortis, 2001). (Intl.-11)

Ex. 11 While the use of computer-based technological applications and tools in language learning programs has been extensively investigated (Chen, 2014; Li, 2012; Liu, 2009; Nami \& Marandi, 2014; Smyth, 2011; Wu \& Marek, 2010), little attention has so far been paid to the teachers' contribution and their perceptions of incorporating technology into their instruction. (Local-12)

Ex. 12 However, for many students, especially those accessing their education through a non-native language, disciplinary vocabulary also remains one of the most challenging areas. (Intl.-15)

Ex. 13 It is worth noting that peer observation of teaching (POT), in the EFL context, is still looked upon with much wariness in most Arab countries due to the confusion between peer observation and regular observation on one hand and summative versus formative observation on the other. (Local-2)

Table 4. Steps and sub-steps in Move 2 (Establishing a niche) in Intl. RAIs

\begin{tabular}{llllllllllllllllll}
\hline Intl. RAs & 1 & 2 & 3 & 4 & 5 & 6 & 7 & 8 & 9 & 10 & 11 & 12 & 13 & 14 & 15 & Total & \# of RAs \\
\hline M2-S1A & 1 & & 4 & 3 & 1 & & 1 & 1 & 4 & & 1 & 2 & 1 & 2 & 2 & 23 & 12 \\
M2-S1B & 2 & 1 & 1 & 1 & & 1 & 1 & 1 & 1 & 1 & & & & 1 & 3 & 14 & 11 \\
Total & 3 & 1 & 5 & 4 & 1 & 1 & 2 & 2 & 5 & 1 & 1 & 2 & 1 & 3 & 5 & 37 & \\
\hline
\end{tabular}

Table 5. Steps and sub-steps in Move 2 (Establishing a niche) in Local RAIs

\begin{tabular}{llllllllllllllllll}
\hline Local RAs & 1 & 2 & 3 & 4 & 5 & 6 & 7 & 8 & 9 & 10 & 11 & 12 & 13 & 14 & 15 & Total & \# of RAs \\
\hline M2-S1A & 1 & 1 & & & & 1 & & 1 & & 1 & & 4 & & 9 & 6 \\
M2-S1B & 2 & 2 & 1 & 1 & 2 & & 1 & & & & 2 & & 1 & 1 & 13 & 9 \\
Total & 0 & 3 & 3 & 1 & 1 & 2 & 1 & 1 & 0 & 1 & 0 & 3 & 0 & 5 & 1 & 22 &
\end{tabular}

Further, while M2-S1B is conventional and M2-S1A is optional in the Local subcorpus, these two sub-steps of Move 2 are conventional in the International subcorpus. This suggests that it is a common strategy of writers of the International RAIs to establish the niche for their studies both in terms of gaps in research (M2-S1A) and real-world matters (M2-S1B). Potential reasons for the lesser employment of sub-steps of Move 1 and the number of RAIs including them in the Local subcorpus could be the influence of the writer's educational 
background (Al-Qahtani, 2006), the avoidance of direct criticism of the work of others (Jogthong, 2001; Taylor \& Tingguang, 1991), and the lack of competition for research space in some cultures (Ahmad, 1997). Based on the findings of this study, it could be suggested that the employment of Move 2 in RAIs may also depend on the publication contexts in which research articles are produced and which have specific readerships that share the same background knowledge.

\subsubsection{Steps in Move 3 (Presenting the Present Work)}

As Table 6 and Table 7 show, out of the seven steps of Move 3, M3-S1 is the most frequently used step in both subcorpora. This step is a relatively obligatory element in both International and Local RAIs (Ex. 14 and Ex. 15). This step occurred 21 times in the International RAIs and 17 times in the Local ones, and the number of the RAIs including them are 15 and 14, respectively.

Ex. 14 This study emerged from a desire to explore how English teachers' revisions differ from those of healthcare professionals, as well as these teachers' attitudes towards their literacy broker role. (Intl.-1)

Ex. 15 The purpose of this study is to investigate a method to teach scientific vocabulary especially those related to Biology in English. (Local-4)

Table 6. Steps in Move 3 (Presenting the present work) in Intl. RAIs

\begin{tabular}{llllllllllllllllll}
\hline Intl. RAs & 1 & 2 & 3 & 4 & 5 & 6 & 7 & 8 & 9 & 10 & 11 & 12 & 13 & 14 & 15 & Total & \# of RAs \\
\hline M3-S1 & 1 & 1 & 1 & 1 & 1 & 1 & 1 & 2 & 2 & 1 & 1 & 2 & 3 & 1 & 2 & 21 & 15 \\
M3-S2 & & & & & 1 & & & & & & & & & & & 1 & 1 \\
M3-S3 & & & & & & & & & & & & & & & & 0 & 0 \\
M3-S4 & & & 1 & 1 & & & & & 2 & & & 1 & & & 1 & 6 & 5 \\
M3-S5 & 1 & & & & 1 & & & & & & & & & & & 2 & 2 \\
M3-S6 & & & & & & & & & & & & & & & & 2 & \\
M3-S7 & & 1 & & 1 & 1 & & & & 1 & & 1 & 1 & & 1 & 2 & 9 & 8 \\
Total & 2 & 2 & 2 & 3 & 4 & 1 & 1 & 3 & 5 & 1 & 2 & 5 & 3 & 2 & 5 & 41 & \\
\hline
\end{tabular}

Table 7. Steps in Move 3 (Presenting the present work) in Local RAIs

\begin{tabular}{llllllllllllllllll}
\hline Local RAs & 1 & 2 & 3 & 4 & 5 & 6 & 7 & 8 & 9 & 10 & 11 & 12 & 13 & 14 & 15 & Total & \# of RAs \\
\hline M3-S1 & 1 & 1 & 1 & 2 & 1 & 1 & 1 & 1 & 2 & 1 & 1 & 1 & 1 & 2 & & 17 & 14 \\
M3-S2 & & & & & & & & & & & & & & & & 0 & 0 \\
M3-S3 & & & 1 & & & & & & & & & & & & & 2 & 2 \\
M3-S4 & & & & & 1 & & & & & 1 & & & 1 & 1 & & 4 & 4 \\
M3-S5 & & 1 & & & & & & 1 & & & & & & & 1 & 3 & 3 \\
M3-S6 & & & & & & & & & 1 & & & & & & & 1 & 1 \\
M3-S7 & & 1 & & 1 & 1 & & & & & 1 & & 1 & & & & 5 & 5 \\
Total & 1 & 3 & 2 & 3 & 3 & 1 & 1 & 2 & 3 & 3 & 1 & 2 & 3 & 3 & 1 & 32 &
\end{tabular}

M3-S7 is the second commonly employed step of Move 3, and while this step is conventional in the International subcorpus, it is optional in Local subcorpus. The following excerpts (Ex. 16 and Ex. 17) are examples of M3-S7 from the two groups of RAIs under analysis.

Ex. 16 By focusing on the analysis of epistemic modality in civil court judgments, we also hope to suggest some pedagogical implications for teaching and learning modality, specifically the discourse and generic variation of modality, in English for Legal Purposes (ELP). (Intl.-12)

Ex. 17 The findings of this study can be of benefit to teachers; both novice and experienced, and to any administration that cares about improving the professional development of its teachers. (Local-2)

M3-S4 is used to realize the communitive function of Move 3 in five International RAIs (6 occurrences) and in four Local RAIs (4 occurrences). This suggests that this step is an optional component of applied linguistics 
RAIs. Moreover, while M3-S3 and M3-S2 disappeared from the international RAIs and Local RAIs, respectively, the other remaining steps (S2, S3, S5, S6) of Move 3 are uncommon in the two subcorpora. Overall, these findings of analysis of steps in Move 3 suggested that there are no striking differences between writers of the sets of texts in terms of using the proposed steps of Move 3 to realize Move 3. Further, the frequent presence of M3-S1 and the relative tendency to employ M3-S7 and M3-S4 in RAIs in both subcorpora indicated that similar rhetorical strategies are followed by writers of applied linguistics in International and Local RAIs. This suggests that the publication contexts (International vs. Local) may not have an impact on the writers' rhetorical choices regarding the employment of particular steps to actualize Move 3.

\section{Conclusion}

The current study was designed to examine the move-step structure of International and Local English-medium RAIs in the field of applied linguistics using Swales' $(1990,2004)$ CARS model. In terms of move analysis, the only difference detected between the two subcorpora was the employment of Move 2, where this move did not always occur in the Local texts analysed. As for the steps and sub-steps, no striking variations were observed between the two sets of texts in the employment of steps and sub-steps of Move 1 and Move 3. The use of the two sub-steps of Move 2 was found to be relatively different in the texts analysed between the International and Local subcorpora. Both disciplinary conventions and contexts of publication of research articles have potential influence on the writers of texts included in the current study regarding the use of individual moves, steps, and sub-steps in applied linguistics RAIs.

The findings of the current study may be valuable for non-native English-speaking writers who are increasingly pressured to publish in international English-medium journals in applied linguistics. These authors of research articles may find the obtained results in this study useful for raising their awareness of the move-step structure of International applied linguistics RAIs, which in turn could increase their chances for their research articles to be accepted for publication in prestigious international journals in their respective fields. It is obvious that the research articles collected for analyses in this study were still inadequate to establish the generalizability of the findings. Therefore, future research can use a larger corpus in order to compare RAIs from these two publication contexts. The present study examined the move-step structure of applied linguistics RAIs in Local and International journals; therefore, future studies employing available models of analysis could examine the move-step structures of other rhetorical sections of applied linguistics research articles in these different publication contexts. For example, Basturkmen's $(2009,2012)$ and Yang and Allison's (2003) move-step models could be used to assess the influence of the publication context when writing RA results and discussion sections in local and international texts.

\section{References}

Ahmad, U. (1997). Research article introductions in Malay: Rhetoric in an emerging research community. In A. Duszak (Ed.), Culture and styles of academic discourse (pp. 273-303). Berlin, Germany: Mouton de Gruyter.

Al-Qahtani, A. A. (2006). A contrastive rhetoric study of Arabic and English research article introductions (Unpublished doctoral thesis). Oklahoma State University, OK, US.

Anthony, L. (1999). Writing research article introductions in software engineering: How accurate is a standard model? IEEE Transactions on Professional Communication, 42, 38-46. https://doi.org/10.1109/47.749366

Árvay, A., \& Tankó, G. (2004). A contrastive analysis of English and Hungarian theoretical research article introductions. International Review of Applied Linguistics in Language Teaching, 42, 71-100. https://doi.org/10.1515/iral.2004.003

Basturkmen, H. (2009). Commenting on results in published research articles and masters dissertations in Language Teaching. Journal of English for Academic Purposes, 8, 241-251. https://doi.org/10.1016/j.jeap.2009.07.001

Basturkmen, H. (2012). A genre-based investigation of discussion sections of research articles in dentistry and disciplinary variation. Journal of English for Academic Purposes, 11, 134-144. https://doi.org/10.1016/j.jeap.2011.10.004

Bhatia, V. K. (1993). Analysing genre: Language use in professional settings. London, UK: Longman.

Bunton, D. (2002). Generic moves in PhD thesis introductions. In J. Flowerdew (Ed.), Academic Discourse (pp. 57-75). Harlow, UK: Longman. 
Crookes, G. (1986). Towards a validated analysis of scientific text structure. Applied Linguistics, 7, 57-70. https://doi.org/10.1093/applin/7.1.57

Dudley-Evans, T. (1986). Genre analysis: An investigation of the introduction and discussion sections of MSc dissertations. In M. Coulthard (Ed.), Talking about text (pp. 128-145). Birmingham, UK: English Language Research, University of Birmingham.

Dudley-Evans, T. (1993). Variation in communication patterns between discourse communities: The case of highway engineering and plant biology. In G. M. Blue (Ed.), Language, Learning and Success: Studying through English (pp. 141-147). London, UK: Macmillan.

Dudley-Evans, T., \& St John, M. J. (1998). Developments in English for specific purposes. A multi-disciplinary approach. Cambridge, UK: Cambridge University Press.

Duszak, A. (1994). Academic discourse and intellectual styles. Journal of Pragmatics, 21, 291-313. https://doi.org/10.1016/0378-2166(94)90003-5

Fakhri, A. (2004). Rhetorical properties of Arabic research article introductions. Journal of Pragmatics, 36, 1119-1138. https://doi.org/10.1016/j.pragma.2003.11.002

Hirano, E. (2009). Research article introductions in English for specific purposes: A comparison between Brazilian Portuguese and English. English for Specific Purposes, 28, 240-250. https://doi.org/10.1016/j.esp.2009.02.001

Jogthong, C. (2001). Research article introductions in Thai: Genre analysis of academic writing (Unpublished doctoral thesis). West Virginia University, Morgantown, West Virginia.

Kanoksilapatham, B. (2003). A corpus-based investigation of scientific research articles: Linking move analysis with multidimensional analysis (Unpublished doctoral thesis). Georgetown University, Washington, D.C.

Kanoksilapatham, B. (2005). Rhetorical structure of biochemistry research articles. English for Specific Purposes, 24, 269-292. https://doi.org/10.1016/j.esp.2004.08.003

Kawase, T. (2018). Rhetorical structure of the introductions of applied linguistics $\mathrm{PhD}$ theses. Journal of English for Academic Purposes, 31, 18-27. https://doi.org/10.1016/j.jeap.2017.12.005

Lee, S. (2000). Contrastive rhetorical study on Korean and English research paper introductions. Journal of Pan-Pacific Association of Applied Linguistics, 4, 316-336.

Loi, C. K. (2010). Research article introductions in Chinese and English: A comparative genre-based study. Journal of English for Academic Purposes, 9, 267-279. https://doi.org/10.1016/j.jeap.2010.09.004

Mackey, A., \& Gass, S. M. (2005). Second language research: Methodology and design. Mahwah, NJ: Lawrence Erlbaum Associates.

Miles, M. B., \& Huberman, A. M. (1994). Qualitative data analysis: An expanded sourcebook (2nd ed.). Thousand Oaks, CA: Sage.

Najjar, H. (1990). Arabic as a research language: The case of agricultural sciences (Unpublished doctoral dissertation). University of Michigan, Ann Arbor, Michigan.

Ono, M. (2017). Move-step Structures of Literature Ph.D. Theses in the Japanese and UK Higher Education. Journal of Writing Research, 8, 469-491. https://doi.org/10.17239/jowr-2017.08.03.03

Ozturk, I. (2007). The textual organisation of research article introductions in applied linguistics: Variability within a single discipline. English for Specific Purposes, 26, 25-38. https://doi.org/10.1016/j.esp.2005.12.003

Samraj, B. (2002). Introductions in research articles: Variations across disciplines. English for Specific Purposes, 21, 1-17. https://doi.org/10.1016/S0889-4906(00)00023-5

Samraj, B. (2004). Discourse features of the student-produced academic research paper: variations across disciplinary courses. Journal of English for Academic Purposes, 3, 5-22. https://doi.org/10.1016/S1475-1585(03)00053-5

Samraj, B. (2005). An exploration of a genre set: Research article abstracts and introductions in two disciplines. English for Specific Purposes, 24, 141-156. https://doi.org/10.1016/j.esp.2002.10.001

Samraj, B. (2008). A discourse analysis of master's theses across disciplines with a focus on introductions. Journal of English for Academic Purposes, 7, 55-67. https://doi.org/10.1016/j.jeap.2008.02.005 
Santos, M. B. D. (1996). The textual organization of research paper abstracts in applied linguistics. Text, 16, 481-499. https://doi.org/10.1515/text.1.1996.16.4.481

Sheldon, E. (2011). Rhetorical differences in RA introductions written by English L1 and L2 and Castilian Spanish L1 writers. Journal of English for Academic Purposes, 10, 238-251. https://doi.org/10.1016/j.jeap.2011.08.004

Soler-Monreal, C. (2016). A move-step analysis of the concluding chapters in computer science PhD theses. Ibérica, 32, 105-132.

Soler-Monreal, C., Carbonell-Olivares, M., \& Gil-Salom, L. (2011). A contrastive study of the rhetorical organisation of English and Spanish PhD thesis introductions. English for Specific Purposes, 30, 4-17. https://doi.org/10.1016/j.esp.2010.04.005

Swales, J. M. (1990). Genre analysis: English in academic and research settings. Cambridge, UK: Cambridge University Press.

Swales, J. M. (2004). Research genres: Explorations and applications. Cambridge, UK: Cambridge University Press. https://doi.org/10.1017/CBO9781139524827

Swales, J. M., \& Najjar, H. (1987). The writing of research article introductions. Written Communication, 4, 175-191. https://doi.org/10.1177/0741088387004002004

Taylor, G., \& Tingguang, C. (1991). Linguistic, cultural, and subcultural issues in contrastive discoure analysis: Anglo-American and Chinese scientific texts. Applied Linguistics, 12, 319-336. https://doi.org/10.1093/applin/12.3.319

Yang, R., \& Allison, D. (2003). Research articles in applied linguistics: Moving from results to conclusions. English for Specific Purposes, 22, 365-385. https://doi.org/10.1016/S0889-4906(02)00026-1 


\section{Appendix A}

\section{The complete list of Intl. and Local RAs}

Intl.-1 Willey, I., \& Tanimoto, K. (2012). “Convenience Editing”' in action: Comparing English teachers' and medical professionals' revisions of a medical abstract. English for Specific Purposes, 31, 249-260.

Intl.-2 Zhang, Z. (2013). Business English students learning to write for international business: What do international business practitioners have to say about their texts? English for Specific Purposes, 32, 144-156.

Intl.-3 Atai, M. R., \& Fatahi-Majd, M. (2014). Exploring the practices and cognitions of Iranian ELT instructors and subject teachers in teaching EAP reading comprehension. English for Specific Purposes, 33, 27-38.

Intl.-4 Dang, T. N. Y., \& Webb, S. (2014). The lexical profile of academic spoken English. English for Specific Purposes, 33, 66-76.

Intl.-5 Martín, P., \& León Pérez, I. K. (2014). Convincing peers of the value of one's research: A genre analysis of rhetorical promotion in academic texts. English for Specific Purposes, 34, 1-13.

Intl.-6 Ockey, G. J. (2014). The potential of the L2 group oral to elicit discourse with a mutual contingency pattern and afford equal speaking rights in an ESP context. English for Specific Purposes, 35, 17-29.

Intl.-7 Trinder, R. (2013). Business students' beliefs about language learning in a university context. English for Specific Purposes, 32, 1-11.

Intl.-8 Pisanski Peterlin, A. (2014). Academic discourse in translation: Trainee translators' performance, experience and perception of rhetorical conventions. English for Specific Purposes, 36, 60-73.

Intl.-9 Webb, S., \& Paribakht, T. S. (2015). What is the relationship between the lexical profile of test items and performance on a standardized English proficiency test? English for Specific Purposes, 38, 34-43.

Intl.-10 Mežek, Š., Pecorari, D., Shaw, P., Irvine, A., \& Malmström, H. (2015). Learning subject-specific L2 terminology: The effect of medium and order of exposure. English for Specific Purposes, 38, 57-69.

Intl.-11 Warren, M. (2013). “Just spoke to ...": The types and directionality of intertextuality in professional discourse. English for Specific Purposes, 32, 12-24.

Intl.-12 Cheng, W., \& Cheng, L. (2014). Epistemic modality in court judgments: A corpus-driven comparison of civil cases in Hong Kong and Scotland. English for Specific Purposes, 33, 15-26.

Intl.-13 Basturkmen, H., \& Shackleford, N. (2015). How content lecturers help students with language: An observational study of language-related episodes in interaction in first year accounting classrooms. English for Specific Purposes, 37, 87-97.

Intl.-14 Bosher, S., \& Stocker, J. (2015). Nurses' narratives on workplace English in Taiwan: Improving patient care and enhancing professionalism. English for Specific Purposes, 38, 109-120.

Intl.-15 Gablasova, D. (2015). Learning technical words through L1 and L2: Completeness and accuracy of word meanings. English for Specific Purposes, 39, 62-74.

Local-1 Abu Radwan, A. (2012). Rhetoric Transfer in L2 Writing: The Role of Second Language Proficiency. Arab World English Journal, 3, 365-399.

Local-2 Shousha, A. (2015). Peer observation of Teaching and Professional Development: Teachers' Perspectives at the English Language Institute, King Abdulaziz University. Arab World English Journal, 6, 131-143.

Local-3 Al Harrasi, K. (2012). The Most Common Spelling Errors among Omani Learners. Arab World English Journal, 3, 96-116.

Local-4 Albakri, R. (2013). Teaching Scientific Vocabulary to EFL Learners Using English: Content and Language Integrated Learning. Arab World English Journal, 4, 267-284.

Local-5 Alkaff, A. (2013). Students' Attitudes and Perceptions towards Learning English. Arab World English Journal, 4, 106-212.

Local-6 Al Hajri, F. (2013). Student Perceptions of the Foundation Programme Assessment in Two Colleges in Oman. Arab World English Journal, 4, 202-222. 
Local-7 Radwan, A. (2014). Gender and Learning Style Preferences of EFL Learner. Arab World English Journal, 5, 21-32.

Local-8 Zoghbor, W. (2014). English Varieties and Arab Learners in the Gulf Cooperation Council (GCC) Countries: Attitude and Perception. Arab World English Journal, 5, 21-32.

Local-9 Alotaibi, H. (2014). Thesis Statement in English Argumentative Essays by Arab Students: A Study of Contrastive Rhetoric. Arab World English Journal, 5, 230-247.

Local-10 AlRousan, R. (2014). Gender and Lexical Features in Jordanian University Students' Use of SMS Messaging. Arab World English Journal, 5, 262-277.

Local-11 Awada, G. (2014). Relative Impact of Windows Movie Maker Journaling on Writing Proficiency and Apprehension. Arab World English Journal, 5, 31-44.

Local-12 Hakim, B (2015). Implementing A Computer Assisted Language Learning Training Program for English Teachers. Arab World English Journal, 6, 100-112.

Local-13 Al-Otaibi, S. (2015). Saudi EFL Students' Knowledge in Pragmatics - Making Requests. Arab World English Journal, 6, 302-315.

Local-14 Alharthi, T. (2015). Adding More Fuel to the Fire: A Study of Attrition in Formulaic Sequences by Adult Learners. Arab World English Journal, 6, 230-243.

Local-15 Omar, N. (2014). The Effectiveness of Feedback on EFL Libyan Writing Context. Arab World English Journal, 5, 326-339.

\section{Copyrights}

Copyright for this article is retained by the author(s), with first publication rights granted to the journal.

This is an open-access article distributed under the terms and conditions of the Creative Commons Attribution license (http://creativecommons.org/licenses/by/4.0/). 